\title{
Final Steps to an All Tungsten Divertor Tokamak
}

\author{
R. Neu*, V. Bobkov, R. Dux, A. Kallenbach, Th. Pütterich, \\ H. Greuner, O. Gruber, A. Herrmann, Ch. Hopf, K. Krieger, \\ C.F. Maggi, H. Maier, M. Mayer, K. Schmid, W. Suttrop, \\ V. Rohde, ASDEX Upgrade team
}

Max-Planck-Institut für Plasmaphysik, EURATOM Association, D-85748 Garching,

Germany

\begin{abstract}
Currently $85 \%$ of the plasma facing components of ASDEX Upgrade are tungsten coated. Carbon influx from W PFCs is still observed but a reduction of the $\mathrm{C}$ content is found in plasma discharges and a lower $\mathrm{C}$ fraction is measured in deposited layers in agreement with modelling. W sputtering from the low field side guard and ICRF limiters is mainly due to fast particles from NBI as well as from ions accelerated in the rectified sheath during ICRF operation. The increase of the W source area is reflected in increased W concentrations. For medium to high density discharges the techniques developed so far, namely central heating and ELM pace-making, allow keeping the $\mathrm{W}$ concentration in the range of $10^{-5}$. Boronisation strongly reduces the $\mathrm{W}$ influxes and similarly the $\mathrm{W}$ content especially during ICRF operation, but this reduction is only temporary and equilibrium is reached already after about 100 discharges.
\end{abstract}


PACS numbers:

52.40.Hf, 52.25.Vy, 52.55.Fa

JNM keywords:

Tungsten, Carbon, Divertor Materials, First Wall Materials, Limiter Materials PSI-17 keywords:

Tungsten, Impurity transport, Impurity source, Carbon impurity, ASDEX-Upgrade

* Corresponding author address: Boltzmannstr.2 85748 Garching

* Corresponding author E-mail: Rudolf.Neu@ipp.mpg.de

Presenting author: Rudolf Neu

Presenting author e-mail: Rudolf.Neu@ipp.mpg.de 


\section{Introduction}

With the decision of building ITER, magnetic confinement fusion research entered a new era. Although the optimization of the plasma performance is still the ultimate goal for an economic use of fusion power, other areas of research gain considerable importance. This is especially true for the plasma wall interaction since the extrapolation from present day devices towards ITER and beyond is largest. ITER [1] still follows a conservative approach using beryllium for the main chamber PFCs in order to minimise the risk of strong power loss through impurity radiation in the central plasma. In a reactor however, Be will not be a viable solution due to its high erosion yield and high- $\mathrm{Z}$ components may have to be used [2,3]. This is the reason why a long term program was started in the divertor tokamak ASDEX Upgrade to implement tungsten PFCs and to explore their feasibility. The area of W-PFCs has been increased steadily since 1999 reaching a fraction of $85 \%$ for the $2005 / 2006$ campaign. The technical solution chosen is of $\mathrm{W}$ coatings on graphite and CFC.

In the following section the rationales for and the tests of the different coatings are presented. Section 3 describes the evolution of the $\mathrm{W}$ concentrations with increasing W area of the PFCs and provides indications for a progressive transition towards a $\mathrm{C}$ free device. The recent $\mathrm{W}$ coating of all poloidal low field side guard and ICRF limiters clearly revealed their dominant role as W source, especially during operation of ICRF. This behaviour is adressed in more detail in Sec. 4. Although ASDEX Upgrade devotes a significant part of its program to $\mathrm{W}$ investigations, several experiments are performed, which intentionally use plasma parameters or/and heating scenarios which are only partially compatible with the W PFCs. This is the reason why boronisations are performed regularily. Their impact on the W influxes and concentrations will be described in 5. Finally, conclusions of the operation with W 
PFCs at ASDEX Upgrade are drawn and further developments as well as potential consequences for a future fusion device are outlined.

\section{The road to an all $\mathrm{W}$ device}

Tungsten has an electrical conductivity 200 times larger than the one of carbon based materials, which would lead to considerably higher load of the support structures due to eddy currents and halo currents if bulk tungsten tiles were used. These higher forces would make the transition from a device designed for C-based PFCs very costly and time consuming and therefore ASDEX Upgrade has chosen the coating solution. In preparatory experiments using markers [4-7], the erosion at different positions of the PFCs has been evaluated and the thickness and the technique of the coating was chosen accordingly $[8,9]$. It turned out that thin coatings $(d<10 \mu \mathrm{m})$ could be reliably produced on graphite using physical vapour deposition (PVD) techniques. These thin coatings withstood power loads of more than $15 \mathrm{MWm}^{-2}$ up to melting conditions and showed very good adhesion when produced by plasma arc deposition [10]. They even survived thermal shocks using an ion beam with power loads above $30 \mathrm{MW} / \mathrm{m}^{-2}$ for $0.3 \mathrm{~s}$, which are expected at the dump regions of the neutral beam injection in case of failure of the primary protection circuits. W coatings on graphite (SGL Carbon R6710) were more reliable than on CFC (Dunlop DMS 704), which can be attributed to the very inhomogeneous surface characteristics and the strong mismatch of thermal expansion coefficients depending on the fibre orientation of the CFC.

Long term marker measurements at the strikepoint region of the lower divertor, which were performed in the last campaign, yielded a $\mathrm{W}$ erosion measured by Rutherford Back Scattering of about $0.2 \mu \mathrm{m}$ per $3040 \mathrm{~s}$ of divertor plasma. However, 
SEM measurements reveal that on a microscopic scale even a complete erosion of the $0.5 \mu \mathrm{m}$ marker can be found. To allow several campaigns with typically 5000 s of divertor plasma each, coatings clearly thicker than $5 \mu \mathrm{m}$ are required. Since PVD coatings in the range of $10 \mu \mathrm{m}$ were found to be prone to delamination [10], vacuum plasma spray (VPS) coatings, similar to the ones used in the ASDEX Upgrade $\mathrm{W}$ divertor experiment [11] are foreseen for the strike point region. Therefore two graphites (SGL Carbon R6710 and Schunk FP479) were coated to a thickness of $d=200 \mu \mathrm{m}$. After initial problems and defects occurring at test tiles used at the low field side auxiliary limiters, reliable VPS coatings were independently developed by Plansee and Sulzer-Metco. They passed successfully thermal screening with power loads up to $23.5 \mathrm{MWm}^{-2}$ as well as cyclic loading at $10 \mathrm{MWm}^{-2}$ [12]. Since 1999 ASDEX Upgrade is being steadily converted from a complete carbon device to one with an almost full $\mathrm{W}$ coverage [13]. The sequential procedure allowed integrating the construction work into the annual repair and upgrading works. Simultaneously, the influence of certain PFCs on the plasma performance (for example operating with a $\mathrm{C}$ or a $\mathrm{W}$ divertor [14]) and mixed material effects could be studied [6]. Fig.1 shows a view into the ASDEX Upgrade vacuum vessel. Currently all PFCs except the strikepoint area of the lower divertor, the horizontal frames of the ICRF antennae and some diagnostic tiles are $\mathrm{W}$ coated, representing a $\mathrm{W}$ area of nearly $36 \mathrm{~m}^{2}$ or about $85 \%$ of all PFCs. The components which were coated most recently are all poloidal low field side (LFS) guard and ICRH limiters, the lower passive stabiliser loop and the roof baffle in the lower divertor as indicated in Fig. 1. The stages of the $\mathrm{W}$ programme are reported in more detail in [15]. 


\section{Evolution of intrinsic impurities}

As expected, the average $\mathrm{W}$ concentration $\left(c_{W}\right)$, which is extracted from spectroscopic measurements (see for example [14]), increased together with the W coverage of the in-vessel surfaces. However, since $\mathrm{W}$ transport is the main parameter determining the central $\mathrm{W}$ concentration $[16,17]$, the source effect is easily obscured. A way to overcome this caveat is to concentrate on identical discharges with a rather high level of transport as presented in [14]. In this case an increase of $c_{W}$ by a factor of ten within the period of 2001/2002 to 2003/2004 (7.1 $\mathrm{m}^{2} \rightarrow 24.8$ $\mathrm{m}^{2}$ W PFCs) could be observed for low density ohmic discharges. However, these discharges represent only a tiny subset of all discharges performed, and therefore a different strategy is pursued here in order to characterize the whole parameter space. Fig. 2 shows all W concentrations, taken during time intervals of sufficiently constant plasma parameters starting with the 2001/2002 campaign. The increase of the area of W coated PFCs from 2001/2002 until now is indicated at the top of the figure. The figure clearly underlines the above mentioned fact because $c_{W}$ different by a factor of 1000 are measured in discharges which are close in time. The increasing number of measurements going from older to more recent discharges originates from the fact that $c_{W}$ above the detection level is found more often, but also that the diagnostics have been steadily improved and the detection limit could be lowered. The data set shows an increase of the centre of gravity of $c_{W}$ up to around discharge $\# 18200$. Only during the present campaign a further increase of $c_{W}$ is found for the discharges with additional wave heating (green and red squares, see below). This is due to a strongly increased W source during ICRF heating, as will be described in the next section. The blue dataset is characterized by the additional condition of an auxiliary heating power $\left(P_{\text {aux }}\right)$ above $7 \mathrm{MW}$, which represents an intermediate value 
at ASDEX Upgrade. The green symbols denote the further subset with more than 2 MW wave heating and finally the red ones represent discharges where in addition $\bar{n}_{e}>7 \cdot 10^{19} \mathrm{~m}^{-3}(50-70 \%$ of the Greenwald density limit, depending on plasma current). For each of the different subsets the range of the observed concentrations narrows. Especially, the constraint on plasma density results in lower $c_{W}$. Together with the techniques developed so far, namely central heating (preferentially ECRH) and ELM pace-making, $c_{W}$ can be kept in the range of $10^{-5}$.

Although the graphite PFCs are reduced to only $15 \%$ of the complete surface, carbon is still existent in the plasma discharges, which could influence the results on the operation with tungsten due to surface layers, edge cooling and $\mathrm{W}$ sputtering by impact of $\mathrm{C}$ ions. However, a survey of the W PFCs in the main chamber performed after the end of the 2005 campaign revealed that only minor amounts of $\mathrm{C}$ are existent in deposited layers. The absolute areal density of the whole layer is smaller than $8 \cdot 10^{22}$ at $\mathrm{m}^{-2}$. More details of this surface analysis are presented in [18]. The long term evolution of the $\mathrm{C}$ content in plasma discharges was evaluated by means of CXR and soft X-ray spectroscopy. The measurements show a reduction by a factor 2-3 of the typical initial values of $c_{C}=1-2 \%$ over the last few years. Modelling with a particle transport and migration code could reproduce this slow reduction process [19]. It reveals that the main ingredients are the strong main chamber recycling and the reduction of the carbon sputtering yield for thin C layers. Additionally, divertor carbon sources are important, contributing significantly to the core $\mathrm{C}$ content by leaking in the range of $10^{19} \mathrm{C}$-atoms/s into the main chamber.

A surprising observation at first glance was the increase of the plasma density during the start-up phase of the plasma compared to the situation with mainly C PFCs. Boronisations can reduce this effect temporarily, but the density quickly recovered after about 20 discharges. Spectroscopic investigations revealed that He plays 
a major role in this process, by supplying up to about $50 \%$ of the electron density during the early (limiter) phase of the discharge. The usual way of operating ASDEX Upgrade with graphite PFCs was to use a He glow discharge (HeGD) inbetween plasma discharges to deplete the D inventory in the PFCs and to reduce the amount of adsorbed impurities. The $\mathrm{W}$ surfaces exhibit a different storage and release characteristics and therefore lead to a higher He content in the plasma. This could be demonstrated clearly by reducing the frequency and duration of HeGD which immediately led to a reduction of He content and density at the beginning of the discharge [20]. Laboratory experiments are under way to reveal the nature of this different behaviour. First results show that the amount of He, which could be stored for typical HeGD impinging energies of a few hundred $\mathrm{eV}$, is larger by up to a factor of three for $\mathrm{W}$, compared to C. However, more important, the stored He is more easily released from $\mathrm{W}$, which could explain the observed behaviour. The temporal behaviour after boronisation relates to the coating with boron and its sequential removal as confirmed by spectroscopic measurements of the $\mathrm{W}, \mathrm{B}$ (see Sec. 5) and C influx (see [19]). Although at first sight the He release is an unwanted property of $\mathrm{W}$ in a low duty cycle device as ASDEX Upgrade it will be an advantage in equilibrium, since large inventories will not build up.

\section{Tungsten Influxes}

As already pointed out earlier [16,14,21], transport plays the major role in determining the $\mathrm{W}$ concentrations in the plasma. However, after having coated all poloidal low field side limiters with $\mathrm{W}$ it became evident that the beneficial influence on central particle transport from central ICRH could be overridden by the increased $\mathrm{W}$ influx leading to an equally radially enhanced W density. A similar be- 
haviour has been reported from the all-molybdenum device Alcator C-Mod when operating with Mo ICRH limiters [22,23]. Therefore, special emphasis was put on the investigation of the W sources, especially during ICRH $[24,25]$. Fifteen linesof-sight are used to measure influx profiles along the limiter height. The set-up allows the simultaneous measurement the W I line at $400.8 \mathrm{~nm}$, a B II at $412.3 \mathrm{~nm}$ and the Balmer- $\delta$ transition at $410.1 \mathrm{~nm}$. The newly installed back-illuminated frametransfer CCD camera increases strongly the temporal resolution enabling ELM resolved influx measurements. The measured photon fluxes are transformed into ion fluxes using photon efficiencies $(S / X B)$. The effective sputtering yields were calculated by dividing the impurity fluxes by the deuterium flux taking the viewing geometry into account [25].

Fig. 3 shows the evolution of the effective sputtering yield, central and edge concentrations of $\mathrm{W}$ together with other plasma parameters in a discharge $\left(I_{p}=0.8\right.$ MA, $B_{t}=-2.5 \mathrm{~T}, \Gamma_{D}=6 \cdot 10^{21} \mathrm{~s}^{-1}$ ) where the distance to the LFS was varied $\left(R_{\text {aus }}\right.$ scan). When the ICRF is switched on, $\Gamma_{W} / \Gamma_{D}=Y_{\text {eff }}^{W}$ immediately increases by more than a factor of five whereas the effective sputtering yield for B, measured on the same lines of sight, stays nearly constant. This immediate reaction suggests that an additional average sheath potential $\Delta \Phi_{r f}$ accelerates the sputtering ions onto the target. Comparing several discharges with ICRF on and off and assuming an admixture of about $1 \%$ light impurities (for example $\mathrm{C}$ ) with an ion charge of $\mathrm{Z}=4$, an increase in the mean sheath potential in the range 1-100 V can be extracted [25] $\left(\Delta \Phi_{r f} \approx 10 \mathrm{~V}\right.$ for the presented discharge). The edge $\mathrm{W}$ concentration (deduced from $\mathrm{W}$ emission at $T_{e} \approx 1 \mathrm{keV}$ ) reflects this initial increase of the source. During the $R_{a u s}$-scan the W yield (and the W flux) varies considerably, reaching almost the pre-ICRF value for the largest distance (smallest $R_{\text {aus }}$ ). However, neither the total radiation nor the edge $\mathrm{W}$ concentration change significantly, suggesting that the W source is shifted away from the limiters towards unobserved locations. The 
central W concentration $\left(T_{e} \geq 2.5 \mathrm{keV}\right)$ drops initially to a value similar to that at the edge, but after rearrangement of the plasma profiles (sawteeth appear from $2.4 \mathrm{~s}$ on) a moderate peaking $\left(c_{W}^{\text {centre }} / c_{W}^{\text {edge }} \approx 3\right)$ of the $\mathrm{W}$ profiles develops. A similar discharge without RF shows a peaking of 10 (see also [14]). This means that due to the increase of the edge concentration the benefit for lower central concentrations gets smaller with the increased W source induced by ICRH. Similarly to the presented $R$-scan, density and $q$ scans were also performed. By varying the edge- $q$ the angle between the field lines and Faraday screens is changed. Depending on the details of the plasma shape, they are nearly parallel for $q_{95} \approx 3$ and lowest electrical fields are expected in this case. However, even for different combinations of $B_{t}$ and $I_{p}$ (performed in the upper divertor) no significant change of the $\mathrm{W}$ influx is found. In a density scan $Y_{\text {eff }}$ could be lowered by a factor of 2 by increasing the gas puff rate by a similar factor. Different to the $R_{a u s}$-scan the reduction of the yield is also reflected in the $\mathrm{W}$ concentrations which decrease also by a factor of 2 .

The influence of medium-Z impurities on the W-sputtering yield at the LFS limiters was demonstrated by the injection of trace amounts of $\operatorname{argon}\left(\Gamma_{A r}=10^{21} \mathrm{~s}^{-1}\right.$ for $50 \mathrm{~ms}$ ). The Ar puff led to a central Ar concentration of $2 \cdot 10^{-4}$, decaying within 200-300 ms. For a period of about $100 \mathrm{~ms}$ the W yield is increased by a factor of 5 . The increased yield is partially reflected in the $\mathrm{W}$ concentration. Interestingly, the increase in the central concentration is larger than at the edge, pointing to a change of central transport due to the additional radiation, as already found in radiative scenarios. Similar experiments without ICRF heating resulted also in an increase of the W yield, but more importantly, they could lead to an unstable situation, because of central accumulation of Ar and W. This behaviour clarifies the fact that the ICRF on one hand increases the W source at the W limiters drastically but on the other hand it can prevent central impurity peaking.

The influence of the ICRF power on the source rate is evaluated in more detail 
in Fig. 4. Here the $\mathrm{W}$ influx from all LFS limiters was added and evaluated during phases with and without ICRH. The ratio $\Delta \Gamma_{W, \text { Lim }}^{I C R F} / \Gamma_{W, \text { Lim }}$ was calculated in the following way: $\left(\Gamma_{W, \operatorname{Lim}}(\mathrm{ICRF}+\mathrm{NBI})-\Gamma_{\mathrm{W}, \operatorname{Lim}}(\mathrm{NBI}\right.$ only $\left.)\right) / \Gamma_{\mathrm{W}, \operatorname{Lim}}(\mathrm{ICRF}+\mathrm{NBI})$. The ICRF induced fraction rises with the power fraction reaching values of $>90 \%$ already at $P_{I C R F} / P_{\text {aux }}=0.5$. Even more strikingly already for the lowest ICRF power fractions, the ICRF induced $\mathrm{W}$ influx dominates. The influx of the LFS limiters is only one possible source of tungsten. In terms of their area (active area $\approx 0.3 \mathrm{~m}^{2}$ ) they represent only a minor fraction of the W PFCs. However, due to the large particle and energy flux densities impinging on them, the W source is easily measurable. In contrast, the area of the central column (heat shield, HS) is much larger (an active area of $8.4 \mathrm{~m}^{2}$ is taken for the assessment), but the $\mathrm{W}$-flux densities are considerably smaller and barely measurable. In order to get hold of the $\mathrm{W}$-flux from the heat shield $\Phi_{W, H S}^{c a l c}$, the measured C flux density is integrated over the whole area and multiplied with the $\mathrm{W}$ erosion yield by $\mathrm{C}$ of $Y_{W}^{C}=10^{-2}$ (representing the yield from $\mathrm{C}^{3+}$ at $T_{e}=10 \mathrm{eV}$ ). Fig. 5 shows the ratio of the measured W influx from the LFS limiters to the calculated W influx from the heat shield for different $P_{\text {aux }}$. For discharges without ICRF heating, the typical ratio is in the range of 1 , suggesting an equal portion from both sources. However as soon as ICRF is used, the ratio increases by a factor 2-10, pointing to considerably higher W fluxes from the (small) limiter area than from the central column. For the highest auxiliary heating powers, the relative importance of the limiters decreases again. The arrow in the figure marks an example for the evolution within a discharge with $10 \mathrm{MW}$ of NBI heating, when adding $3 \mathrm{MW}$ of ICRF heating.

All of the above statements are made for ELM integrated measurements. Results for ELM resolved measurements are presented in [25]. It is found that independently of the ELM energy the effective yield for W is increased during an ELM by a factor of 10 and that the total $\mathrm{W}$ flux is dominated by the sputtering during ELMs 
$(\approx 70 \%)$. However due to the fact that the ELM energy is decreasing inversely to their frequency, this value is almost constant for type I ELMy H-Modes in ASDEX Upgrade.

\section{Effect of boronisation}

ASDEX Upgrade devotes a significant part of its program to the $\mathrm{W}$ investigations. Part of this is the development of integrated scenarios, to demonstrate the operation in $\mathrm{C}$ free machine by using noble gas injection together with ELM pacemaking and central heating (see for example [26]). But there are also several experiments, which intentionally use plasma parameters or/and heating scenarios that are not very compatible with the W PFCs. For this reason reason boronisations are regularly performed [20], to access and to explore a large working space. Boronisations strongly reduce the impurity level in ASDEX Upgrade. Oxygen plays only a significant role shortly after a major vent [20]. In contrast, the content of medium- $Z$ impurities such as $\mathrm{Fe}$ and $\mathrm{Cu}$, which are also existent in the plasma (see for example [27]), as well as W are strongly suppressed (1-2 orders of magnitude) under otherwise similar conditions.

The reduction of $\mathrm{W}$-influxes and the temporal evolution of the boron coverage is especially evident in ICRH dominated discharges. This can be measured in identical discharges, which are run every day of operation. They are ohmic $\left(I_{p}=0.8\right.$ MA, $B_{t}=-2.0 \mathrm{~T}$, so called ohmic standard discharge) except for a short pulse of

$0.5 \mathrm{~s}$ of $1.8 \mathrm{MW}$ ICRF heating at a target density of $n_{e}=3.5 \cdot 10^{19} \mathrm{~m}^{-3}$. Fig.6 shows the $\mathrm{W}$-influxes $\left(\Gamma_{W}\right)$ and the effective yields $\left(\Gamma_{W} / \Gamma_{D}\right)$ at the ICRF limiters and guard limiters as well as $\mathrm{W}$ densities $\left(n_{W}\right)$ versus number of discharges after a boronisation. For a fresh boronisation an H-Mode is achieved, which increases 
the plasma density considerably. For this reason $n_{W}$ is given instead of $c_{W}$ for easier comparison with the influxes. As can be deduced from the upper two parts of the figure, the effect of boronisation at the ICRF limiters is only very transient and equilibrium is reached already after 20 discharges. This observation is in line with estimates taking into account the measured hydrogen flux and an effective boron erosion yield below $1 \%$ at the ICRF limiter. For the guard limiters the time-constant is considerably larger reflecting the smaller particle and energy load. The W density recovery occurs on an intermediate timescale, suggesting that the ICRF limiters are not the only significant source during ICRF heating as already presented in Fig. 4. In order to exclude effects of boronisation on the investigation presented in Sec. 4, all analyzed discharges were taken at least 40 discharges after boronisation.

Further evidence for the long term evolution of the $\mathrm{W}$ concentration and other important plasma parameters after boronisation can be deduced from the comparison of \#21031 (shown in Fig.3, 45 discharges after boronisation) and the identical discharge \#20982 ( $\approx 150$ discharges after boronisation). In both cases the external gas puff, the plasma shape and the addition heating were set identical. In discharge \#20982 the total radiation was higher by $30 \%$ (4 MW) and $\bar{n}_{e}$ was higher by $10 \%$, which partly accounts for the higher radiation. When comparing the radiation profiles, which are hollow in both discharges, an overall increase of the radiation power density by a factor of 2 inside the normalised poloidal radius $\rho_{p o l}=0.8$ is found. In contrast the stored energy was identical in both discharges and the effective B yield was lower by a factor of two. The tungsten effective yield was increased by about $50 \%$ and its edge and central concentration were larger by a factor of 3 . These values demonstrate the further reduction of B coverage, which was already in \#21031 close to equilibrium, and support the consistent picture that the observed limiters were already closer to equilibrium than other surfaces (see also [19] for timescales). Additionally it suggests that the $\mathrm{W}$ radiation is not dominant for \# 21031 because 
of the moderate increase of $P_{\text {rad }}$ for tripled $c_{W}$.

\section{Conclusion and Outlook}

In the present campaign ASDEX Upgrade is equipped with an area of about 36 $\mathrm{m}^{2}$ of $\mathrm{W}$ coated tiles, representing about $85 \%$ of all PFCs. The main newly added components are the low field side poloidal guard limiters, the roof baffle in the lower divertor and the lower passive stabilizer loop. The increased W-area results in higher W concentrations in the plasma. Especially the LFS limiters represent a significant W source mainly during ICRF operation. The beneficial effect of central (wave) heating is still valid, however under certain circumstances (for example dominant ICRF) this effect is overridden by an enhanced W concentration over the whole plasma radius due to the high $\mathrm{W}$ influx. Investigations have been performed to characterize the erosion mechanism during ICRF heating and indications for an increase of the sheath potential have been found. The effect of the strong source could only be significantly reduced when increasing the density. Increasing the distance of the plasma from the limiter resulted only in a reduction of the local source at the limiter but the edge $\mathrm{W}$ density remained unchanged pointing to a compensating increase elsewhere. This behaviour made the balance of the heating methods more delicate and suggests a preferential use of ECRH for central heating. The basis for this procedure is already laid, because a two frequency $(104 / 144 \mathrm{GHz})$ long pulse gyrotron is set-up and a multi-frequency gyrotron will be installed soon, allowing to operate at a large range of toroidal fields. Concomitantly with the increase of the W surface an increase of the He concentration was observed in the plasma. Investigations show that the storage and release of $\mathrm{He}$ from $\mathrm{W}$ surfaces is different from that from graphite. After adjusting our operating parameters, the He content, 
which originated from HeGDs could be reduced again to an acceptable level. Clear indications for the reduction of the carbon content are found during the last two years. The slow decrease of the $\mathrm{C}$ concentration can be explained by strong main chamber recycling. Additionally, it was found that the divertor carbon source contributes significantly to the core $\mathrm{C}$ content by leaking into the main chamber. This behaviour will be examined in more detail [19], because it makes the use of CFC at the strikepoints of ITER even more questionable. A faster reduction of the $\mathrm{C}$ content in the plasma is expected as soon as the strikepoint region of the lower divertor is coated with W. The cryo-pump and the turbo-molecular pumps act as strong sink of hydrocarbons during the discharges. From the measured pumping rate of $6 \cdot 10^{18}$ at $s^{-1}$ [28] a rapid depletion of $C$ can be expected after the elimination of primary sources especially, since a rather low $\mathrm{C}$ deposition is found already at present in the main chamber [18]. The elimination of all uncoated graphite tiles is foreseen for the next campaign. Thick VPS coatings ( $200 \mu \mathrm{m}$ instead of 3-5 $\mu \mathrm{m}$ ) have been successfully tested and will be ready for installation. A dedicated program will then be run in ASDEX Upgrade with no or very few boronisations, to investigate the compatibility of a W first wall and divertor with reactor scenarios. So far, boronisations have been performed regularly in order to permit a broad range of experiments, which partly are orthogonal to the requirements identified for W PFCs, such as low edge densities, off axis heating, counter NBI, etc.. These experiments were grouped right after boronisations for most efficient use of the experimental time. However, the observed time scales for the recovery of $\mathrm{W}$ influx and $\mathrm{W}$ concentrations suggest that ITER-like high density operation with significant heating power from NBI and ICRF is feasible without relying on the beneficial effect of covering the $\mathrm{W}$ components by boronisations. 


\section{References}

[1] R. Aymar, P. Barabaschi, and Y. Shimomura, Plasma Phys. Controlled Fusion 44, 519 (2002).

[2] G. Janeschitz, P. Barabaschi, G. Federici, K. Ioki, P. Ladd, V. Mukhovatov, M. Sugihara, and R. Tivey, Nucl. Fusion 40, 1197 (2000).

[3] H. Bolt, V. Barabash, W. Krauss, J. Linke, R. Neu, S. Suzuki, T. Yoshida, and ASDEX Upgrade Team, J. Nucl. Mater. 329-333, 66 (2004).

[4] D. Naujoks, J. Roth, K. Krieger, G. Lieder, and M. Laux, J. Nucl. Mater. 210, 43 (1994).

[5] K. Krieger, H. Maier, R. Neu, and ASDEX Upgrade Team, J. Nucl. Mater. 266-269, 207 (1999).

[6] K. Krieger, J. Likonen, M. Mayer, R. Pugno, V. Rohde, E. Vainonen-Ahlgren, and ASDEX Upgrade Team, J. Nucl. Mater. 337-339, 10 (2005).

[7] H. Maier and ASDEX Upgrade Team, J. Nucl. Mater. 335, 515 (2004).

[8] C. García-Rosales, S. Deschka, W. Hohenauer, R. Duwe, E. Gauthier, J. Linke, M. Lochter, W. K. W. M. Malléner, L. Plöchl, P. Rödhammer, A. Salito, and ASDEX Upgrade Team, Fusion Tech. 32, 263 (1997).

[9] H. Maier, J. Luthin, M. Balden, S. Lindig, J. Linke, V. Rohde, H. Bolt, and ASDEX Upgrade Team, J. Nucl. Mater. 307-311, 116 (2002).

[10] H. Maier, J. Luthin, M. Balden, M. Rehm, F. Koch, and H. Bolt, Surface and Coating Technology 142-144, 733 (2001).

[11] R. Neu, K. Asmussen, S. Deschka, A. Thoma, M. Bessenrodt-Weberpals, R. Dux, W. Engelhardt, J. C. Fuchs, J. Gafert, C. García-Rosales, A. Herrmann, K. Krieger, 
F. Mast, J. Roth, V. Rohde, M. Weinlich, U. Wenzel, ASDEX Upgrade Team, and ASDEX NI Team, J. Nucl. Mater. 241-243, 678 (1997).

[12] R. Neu et al., submitted to Physica Scripta (2006).

[13] R. Neu, R. Dux, A. Geier, O. Gruber, A. Kallenbach, K. Krieger, H. Maier, R. Pugno, V. Rohde, S. Schweizer, and ASDEX Upgrade Team, Fusion Eng. Design 65, 367 (2003).

[14] R. Neu, R. Dux, A. Kallenbach, T. Pütterich, M. Balden, J. C. Fuchs, A. Herrmann, C. F. Maggi, M. O’Mullane, R. Pugno, I. Radivojevic, V. Rohde, A. C. C. Sips, W. Suttrop, A. Whiteford, and ASDEX Upgrade Team, Nucl. Fusion 45, 209 (2005).

[15] R. Neu et al., submitted to J. Nucl. Mater. (2006).

[16] R. Dux, R. Neu, C. F. Maggi, A. G. Petters, R. Pütterich, G. Pereverzev, A. Mück, F. Ryter, J. Stober, B. Zaniol, and ASDEX Upgrade Team, Impurity Transport and Control in ASDEX Upgrade, in Proc. of the 20th IAEA Conference Fusion Energy (CD-Rom), Vilamoura, Portugal, November 2004, volume IAEA-CSP-25/CD, pp. IAEA-CN-116/EX/P6-14, Vienna, 2005, IAEA.

[17] R. Neu, R. Dux, A. Geier, H. Greuner, K. Krieger, H. Maier, R. Pugno, V. Rohde, S. W. Yoon, and ASDEX Upgrade Team, J. Nucl. Mater. 313-316, 116 (2003).

[18] C. Hopf et al., PSI 2006, Hefei, submitted to J. Nucl. Mater. (2006).

[19] A. Kallenbach et al., PSI 2006, Hefei, submitted to J. Nucl. Mater. (2006).

[20] V. Rohde et al., PSI 2006, Hefei, submitted to J. Nucl. Mater. (2006).

[21] A. Kallenbach, R. Neu, R. Dux, H.-U. Fahrbach, J. C. Fuchs, L. Giannone, O. Gruber, A. Herrmann, P. T. Lang, B. Lipschultz, C. F. Maggi, J. Neuhauser, V. Philipps, T. Pütterich, V. Rohde, J. Roth, G. Sergienko, A. Sips, and ASDEX Upgrade Team, Plasma Phys. Controlled Fusion 47, B207 (2005). 
[22] M. May, K. Fournier, J. Goetz, J. Terry, D. Pacella, M. Finkenthal, E. Marmar, and W. Goldstein, Plasma Phys. Controlled Fusion 41, 45 (1999).

[23] B. Lipschultz, D. Pappas, B. LaBombard, J. Rice, D. Smith, and S. Wukitch, Nucl. Fusion 41, 585 (2001).

[24] V. Bobkov et al., PSI 2006, Hefei, submitted to J. Nucl. Mater. (2006).

[25] R. Dux et al., PSI 2006, Hefei, submitted to J. Nucl. Mater. (2006).

[26] A. Kallenbach, P. T. Lang, R. Dux, C. Fuchs, A. Herrmann, H. Meister, V. Mertens, R. Neu, T. Pütterich, T. Zehetbauer, and ASDEX Upgrade Team, J. Nucl. Mater. 337$339,732(2005)$.

[27] V. Schustereder et al., PSI 2006, Hefei, submitted to J. Nucl. Mater. (2006).

[28] V. Rohde, R. Dux, M. Mayer, R. Neu, T. Pütterich, W. Schneider, and ASDEX Upgrade Team, Physica Scripta T111, 49 (2004). 


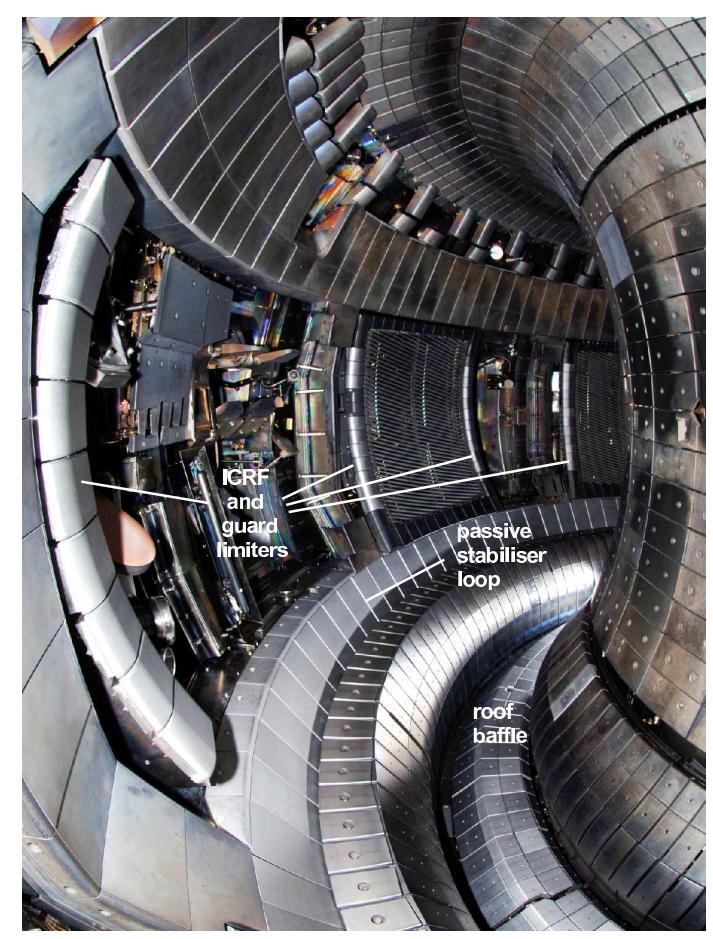

Fig. 1. View into the ASDEX Upgrade vacuum chamber. All major PFC, except the strikepoint region of the lower divertor are $W$ coated. The most recently installed W-coated PFCs are indicated. 


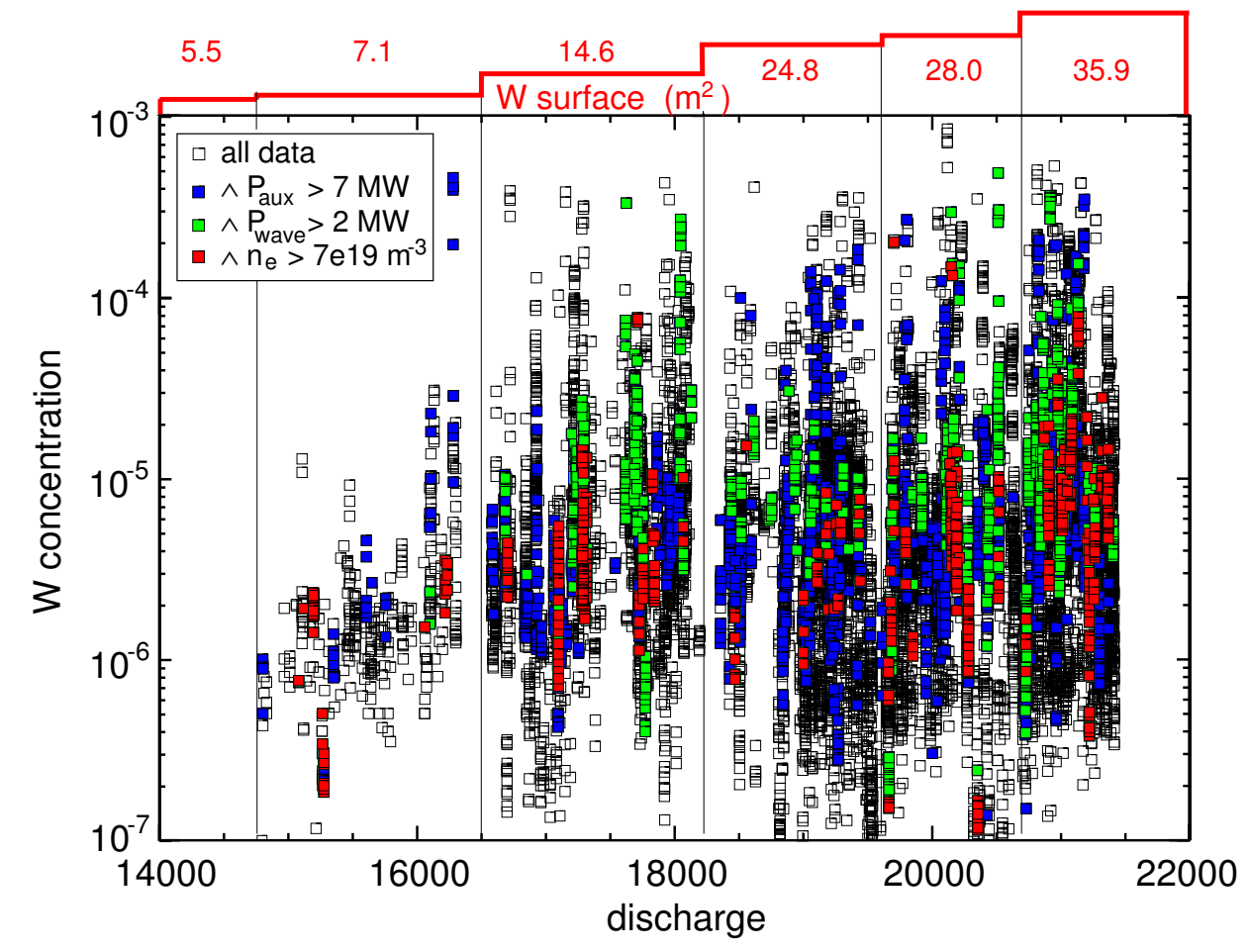

Fig. 2. Database of W concentrations, taken during time intervals of sufficiently constant plasma parameters starting with the 2001/2002 campaign. The increase of the area of W coated PFCs is indicated at the top of the figure. Each of the coloured symbols gives a subset of the previous one with the additional constraint given in the inset. 


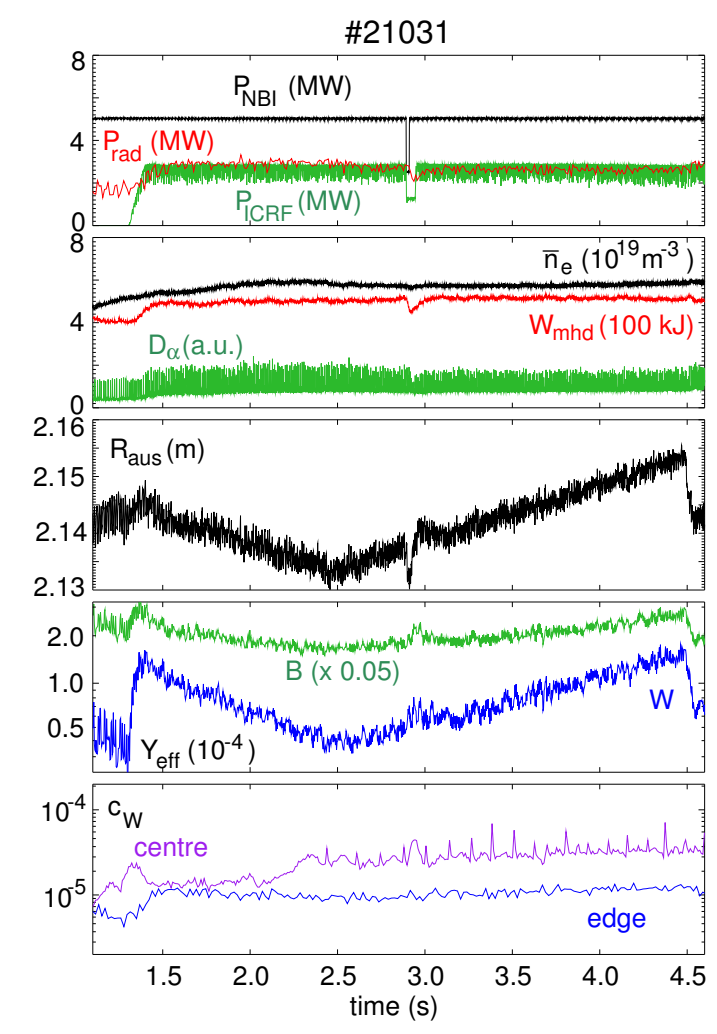

Fig. 3. Plasma parameters, effective $W$ and $B$ sputtering yields $\left(Y_{\text {eff }}\right)$ and $W$-concentration $\left(c_{W}\right)$ of discharge \# 21031 during a scan of the outer plasma radius $\left(R_{\text {aus }}\right)$.

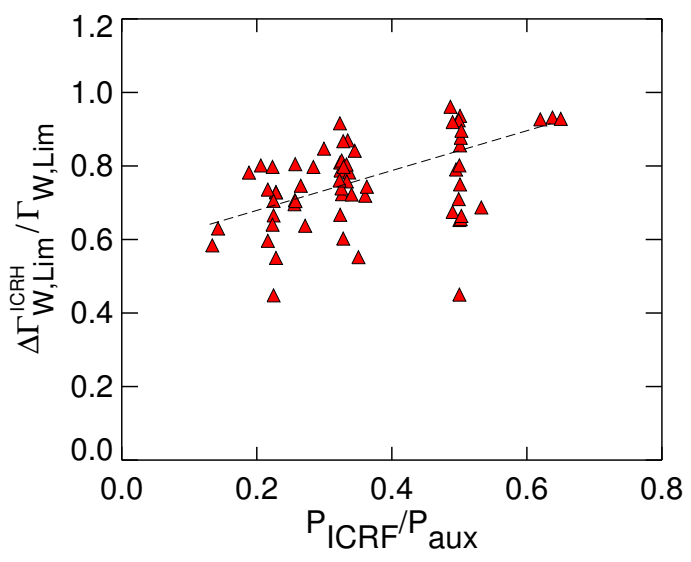

Fig. 4. Increase of W influx from all LFS limiters due to ICRF $\left(\Delta \Gamma_{W, L i m}^{I C R F} / \Gamma_{W, L i m}\right)$ as a function of the ICRF power fraction. The line is drawn only to guide the eye. 


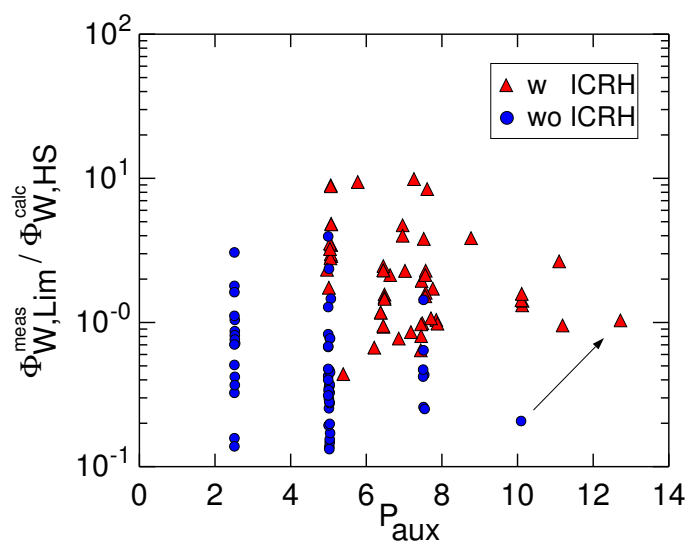

Fig. 5. Ratio of the W source at the LFS limiters over that at the heat shield $\left(\Phi_{W, L i m}^{\text {meas }} / \Phi_{W, H S}^{\text {calc }}\right)$ during ICRF+NBI and NBI only as a function of the total auxiliary heating power $\left(P_{a u x}\right)$. Note that the influx from the limiters is measured whereas the one from the heat shield is only derived from the measured C influx using an effective sputtering yield of 0.01 .

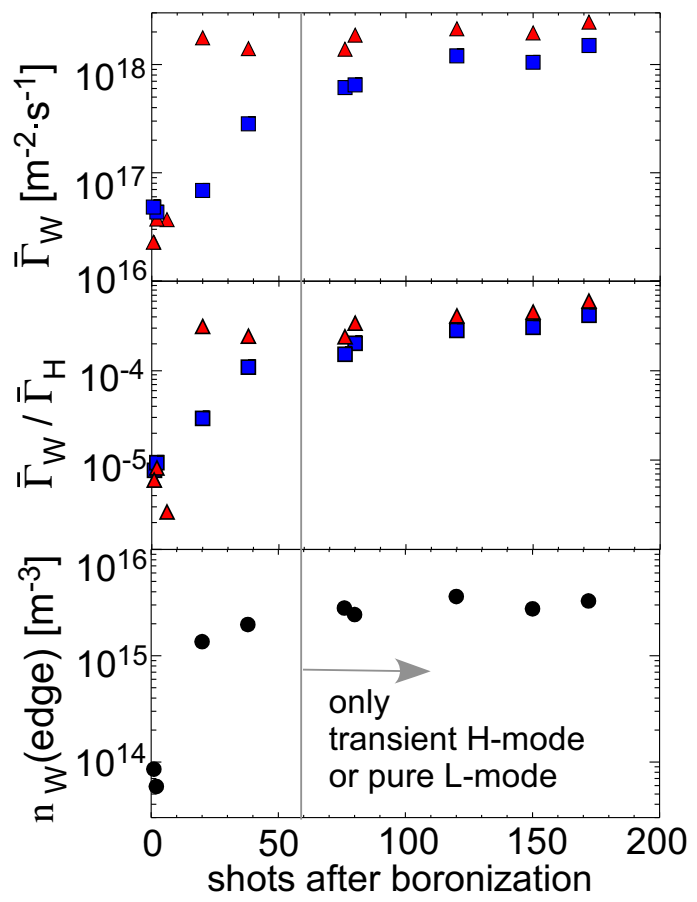

Fig. 6. Evolution of W-influxes $\left(\Gamma_{W}\right)$, effective yields $\left(\Gamma_{W} / \Gamma_{D}\right)$ at the ICRF limiters (triangles) and guard limiters (squares) as well as $W$ densities $\left(n_{W}\right)$ versus distance to a boronisation during identical discharges (see text for details). 